\title{
Aplicação e análise de indicadores de mobilidade urbana sustentável para transporte não motorizado na cidade de São Carlos-SP1
}

\section{Application and analysis of sustainable urban mobility indicators for non-motorized transport in the city of São Carlos-SP}

\author{
França, Paola M. R. L.; Guerreiro, Thais C. M. \\ Universidade Federal de São Carlos, Brasil - paola.lescura@gmail.com \\ Universidade Federal de São Carlos, Brasil - tcmguerreiro@ufscar.com
}

\begin{abstract}
RESUMO
Incentivos ao transporte motorizado, sobretudo aos privados, e a insuficiência dos transportes públicos provocam impactos diretos no comportamento urbano e no processo de crescimento das cidades. Como consequência, verifica-se a insustentabilidade do padrão de mobilidade atual, além da ocorrência de problemas relacionados à questão ambiental. Nesta pesquisa houve a aplicação e avaliação dos indicadores de transporte não motorizado referente ao cálculo do Índice de Mobilidade Urbana Sustentável (IMUS), que consiste numa ferramenta de análise da qualidade e sustentabilidade da mobilidade urbana de cidades de médio porte desenvolvida em 2008. O objetivo foi verificar potenciais formas de otimização e obtenção dos resultados e a comparação dos resultados com os obtidos no ano de 2008 na cidade de São Carlos - SP. Esperou-se obter conclusões a respeito da eficiência das medidas adotadas no intervalo de tempo entre as pesquisas. Os resultados obtidos mostraram que o índice teve um acréscimo de $12 \%$ em sua pontuação em 10 anos. Foi possível identificar melhorias a serem feitas nos indicadores estudados. $O$ trabalho trouxe conclusões a respeito das ações que vêm sendo feitas, e assim, podendo contribuir para a gestão municipal futura no sentido de fornecer diretrizes para uma mobilidade mais sustentável.
\end{abstract}

Palavras-chave: Mobilidade, Sustentabilidade, Indicadores, Transportes não motorizados, São Carlos.

\begin{abstract}
Incentives to motorized transport, especially to the private ones, and the insufficiency of the public transports provoke direct impacts in the urban behavior and in the process of growth of the cities. As a consequence, the current mobility pattern is unsustainable, as well as the occurrence of problems related to the environmental issue. In this research, the non-motorized transport indicators for the calculation of the Sustainable Urban Mobility Index (IMUS) were applied and evaluated, which is a tool for analyzing the quality and sustainability of urban mobility in medium-sized cities developed in 2008. The objective was to verify potential forms of optimization and obtaining the results and the comparison of the results with those obtained

${ }^{1}$ FRANÇA, Paola M. R. L.; GUERREIRO, Thais C. M. Aplicação e análise de indicadores de mobilidade urbana sustentável para transporte não motorizado na cidade de São Carlos-SP. In: II SIMPÓSIO NACIONAL DE GESTÃO E ENGENHARIA URBANA: SINGEURB, 2019, São Paulo. Anais... Porto Alegre: ANTAC, 2019.
\end{abstract}


in the year 2008 in the city of São Carlos - SP. The results showed that the index had an increase of $12 \%$ in its score in 10 years. It was possible to identify improvements to be made in the indicators studied. The work brought conclusions about the actions that have been done, and thus, being able to contribute to future municipal management in order to provide guidelines for a more sustainable mobility.

Keywords: Mobility, Sustainability, Indicators, Non-motorized transport, São Carlos

\section{INTRODUÇÃO}

No Brasil, a população rural prevaleceu sobre a urbana até a década de 40 do século XX (IBGE, 2010). Naquela época os principais meios de transporte da população eram a bicicleta, a charrete, o cavalo, o trem e, para poucos, o carro. Na década de 50, o governo de Juscelino Kubistchek, consagrado pela frase "Governar é abrir estradas" implantou o "Modelo Rodoviarista" no Brasil a fim de incentivar a instalação de indústrias automobilísticas no país. Os governos militares, que vieram posteriormente, tinham o propósito de "Integrar (o território) para não entregar (os recursos)" e, com isso, mantiveram a política. Todas essas ações foram muito relevantes para que a predominância do modal rodoviário que se tem hoje no país acontecesse. Em adição, muitos incentivos ao transporte motorizado, sobretudo ao privado, foram praticados pelos governos. Esses fatores, somados à insuficiência dos transportes públicos, que, como dito, eram em extrema maioria do modal rodoviário, provocaram impactos no comportamento urbano e no processo de crescimento das cidades. Por consequência, o país vem enfrentando o problema da mobilidade urbana $e$ este, no ponto de vista da maioria da população, parece ser de difícil solução.

Somada aos problemas de mobilidade que grande parte das cidades brasileiras enfrenta há certo tempo, surgiu a questão ambiental: o padrão de mobilidade que favorece os modais motorizados e individuais tem se mostrado cada vez mais insustentável.

Em 1987, a Comissão Mundial sobre Meio Ambiente e Desenvolvimento elaborou uma definição de sustentabilidade como "O desenvolvimento sustentável garante a satisfação das necessidades do presente sem comprometer a capacidade de as gerações futuras satisfazerem as suas próprias necessidades".

No Brasil, a Lei Federal $n^{\circ} 12.587$ de 2012 foi instituída frente à necessidade de mudança intensa nos padrões da mobilidade. A lei em questão trata dos princípios, diretrizes e instrumentos da Política Nacional de Mobilidade Urbana (BRASIL, 2012).

Mesmo sendo anterior à Lei $n^{\circ} 12.587$, o Índice de Mobilidade Urbana Sustentável (IMUS) elaborado e proposto por Costa (2008), se mostrou uma boa ferramenta para avaliar indicadores da qualidade e sustentabilidade da mobilidade urbana de cidades de médio porte, tendo em vista as aplicações que já foram feitas. Isso mostrou a necessidade de estudo do tema, mesmo ainda não havendo uma lei específica para tal. Ainda assim, algumas adaptações e atualizações ainda precisam ser feitas, segundo a própria autora, para seu aperfeiçoamento.

São Carlos, uma das cidades onde se aplicou o índice, passou por diversas transformações no aspecto da infraestrutura urbana e de transportes desde que a avaliação em questão foi feita. Além disso, a demanda pelos modais coletivos e a necessidade do uso do transporte não motorizado cresceram com o desenvolvimento da cidade.

O objetivo geral desta pesquisa é realizar uma reaplicação dos indicadores de transporte não motorizado referentes ao cálculo do Índice de Mobilidade Urbana Sustentável (IMUS), tendo em vista o tempo de 10 anos desde sua elaboração e aplicação inicial. A decisão de se trabalhar exclusivamente com a seção de indicadores referente ao transporte não motorizado foi dada devido ao curto período de tempo destinado ao desenvolvimento deste trabalho e à importância do favorecimento dos transportes ativos. 


\section{REVISÃO BIBLIOGRÁFICA}

Nesta seção serão apresentadas as informações necessárias para contextualizar e basear as análises do objeto de estudo.

\subsection{Mobilidade Urbana}

A mobilidade urbana, segundo o Ministério das Cidades, pode ser definida como um atributo das cidades que se refere à propriedade de deslocamentos de pessoas e bens no espaço urbano. Órgãos gestores municipais devem prover a infraestrutura necessária para esses transportes, priorizando sempre os coletivos e integrando modos motorizados e não motorizados. (Brasil, 2016).

\subsection{Mobilidade Urbana Sustentável}

A mobilidade urbana sustentável pode ser alcançada sob dois enfoques: adequando a oferta de transporte ao contexto socioeconômico local ou relacionando a mobilidade urbana com a qualidade ambiental. Para o primeiro caso, medidas de associação do transporte ao desenvolvimento urbano e à equidade social em relação aos deslocamentos são necessárias. Para o segundo, o modo de transporte a ser utilizado e a tecnologia são chaves para a questão (CAMPOS; RAMOS, 2005). Resumidamente, percebe-se que a questão relacionada à sustentabilidade da mobilidade está estritamente ligada a dispersão do uso do solo urbano.

\subsection{Sistema de mobilidade urbana e transporte não-motorizado}

O Sistema Nacional de Mobilidade Urbana é definido no art. $3^{\circ}$ Lei n. 12.587/2012 como o conjunto organizado e coordenado dos modos de transporte, de serviços e de infraestruturas que garantem os deslocamentos de pessoas e cargas no território do município. Esse sistema possui componentes que permitem seu funcionamento, são eles: os modais de transporte não motorizados e os motorizados, que, por sua vez, podem ser privados ou públicos (BRASIL, 2012).

A prioridade do transporte não motorizado sobre o transporte motorizado individual é garantida pela Lei n. 12.587/2012 para todas as cidades.

\subsection{Indicadores}

De acordo com GUDMUNDSSON (2004), os indicadores são variáveis selecionáveis que auxiliam os objetivos a se tornem operacionais e a diminuir a complexidade da gestão de sistemas. Os indicadores podem desempenhar função de balizadores nas análises técnicas e na criação de políticas públicas. Uma vez relacionados a metas, são capazes de avaliar performances, mostrando as condições de uma política ou de um sistema como todo.

\section{5 Índice de Mobilidade Urbana Sustentável (IMUS)}

O Índice de Mobilidade Urbana Sustentável (IMUS), proposto por Costa (2008), foi desenvolvido com base em estudos de metodologias de apoio à decisão. Seu processo de desenvolvimento foi estruturado a partir (i) da definição dos objetivos para a sustentabilidade urbana, (ii) do escopo, (iii) da escolha de uma estrutura apropriada, (iv) da definição de critérios para seleção de indicadores, (v) da identificação de um conjunto de potenciais indicadores, (vi) da avaliação e seleção do conjunto final de indicadores, (vii) da coleta de dados e análise dos resultados, (viii) da preparação e apresentação do relatório de sustentabilidade urbana e (ix) da avaliação do desempenho dos indicadores. As informações e características referentes ao IMUS estão apresentadas na figura 1. 
Figura 1 - Definição e caracterização do IMUS.

\section{Índice de Mobilidade Urbana Sustentável - IMUS}

\section{Principais caracteristicas}

O IMUS consiste em uma ferramenta desenvolvida para auxiliar no monitoramento e análise da mobilidade urbana e também na elaboraçäo de políticas públicas visando a melhoria da qualidade de vida e a sustentabilidade dos sistemas de mobilidade

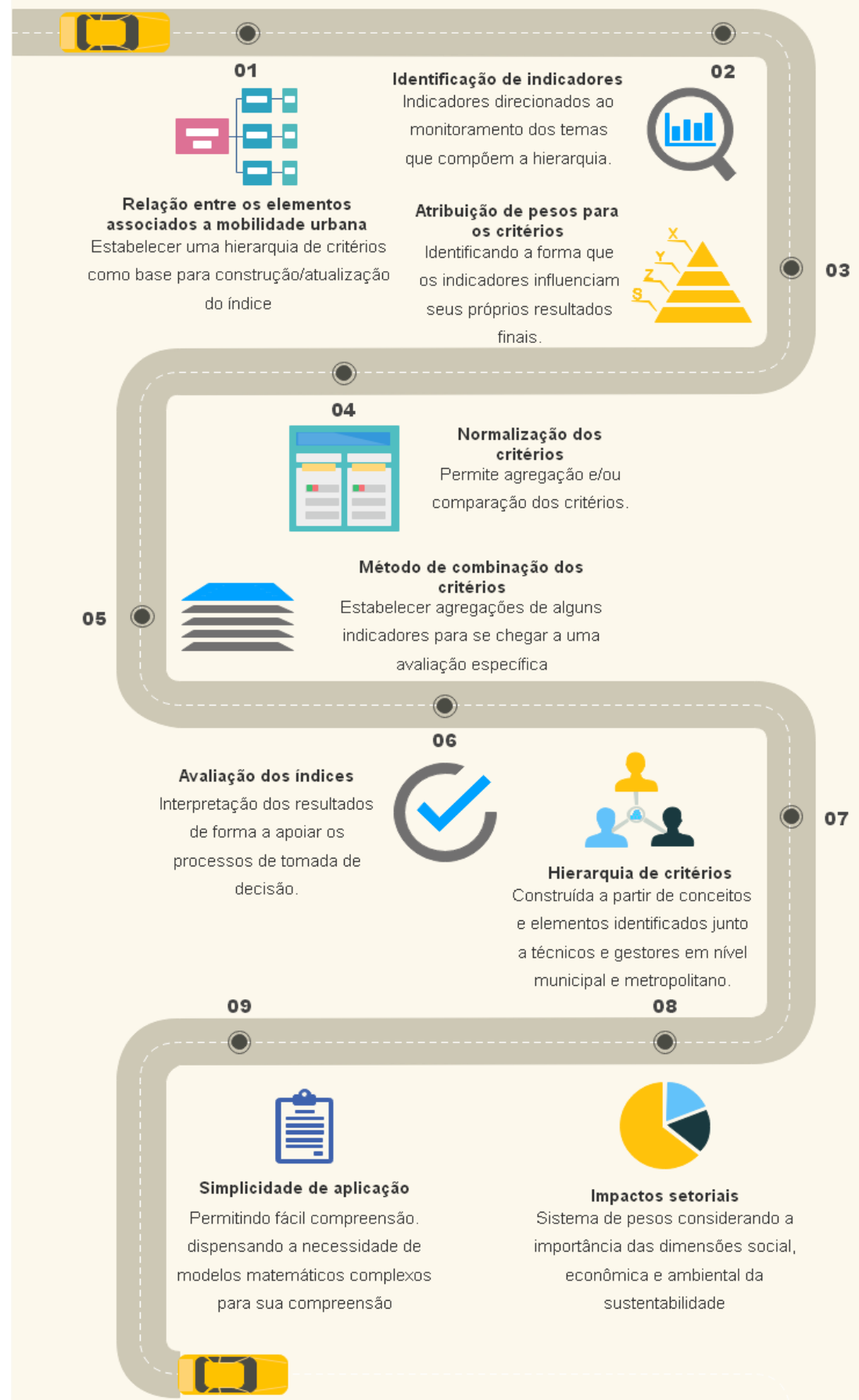

Fonte: Adaptado de Costa (2008). 


\section{METODOLOGIA}

O presente trabalho teve como principal característica de metodologia a coleta e avaliação de indicadores de mobilidade urbana sustentável. Como se trata de um estudo baseado em outro trabalho, realizado por Costa em 2008, o método de aplicação foi semelhante ao da referência. No intuito de facilitar a compreensão da metodologia, foi elaborado um fluxograma, ilustrado figura 2.

Figura 2 - Fluxograma da metodologia.

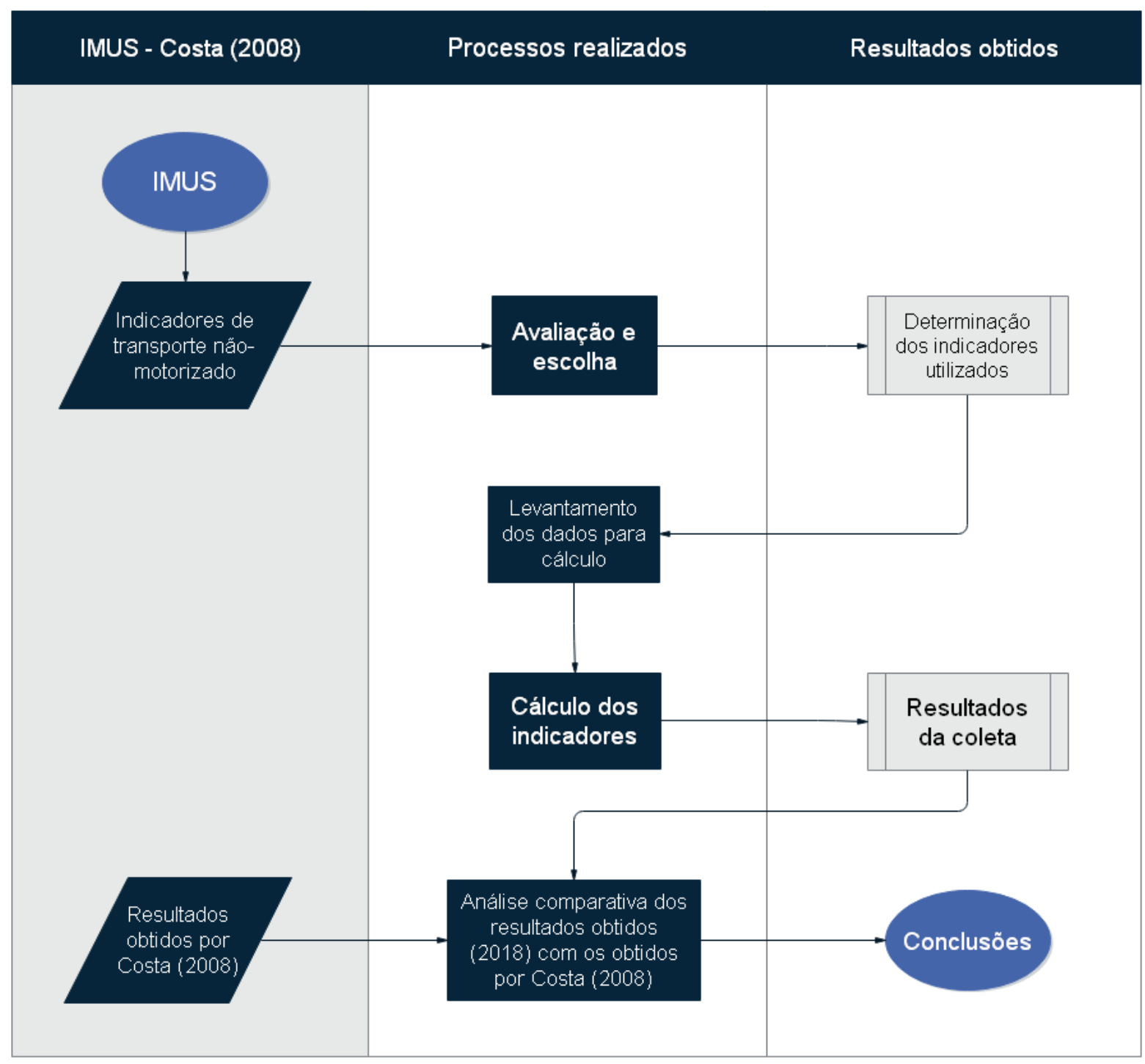

Fonte: Os autores (2018).

Para cada indicador, apresenta-se uma figura com as informações principais: definições, método de cálculo, valor de referência para pontuação do índice e score com os dados obtidos em 2018. Os indicadores escolhidos para este trabalho estão na figura 3. 
Figura 3 - Indicadores escolhidos.

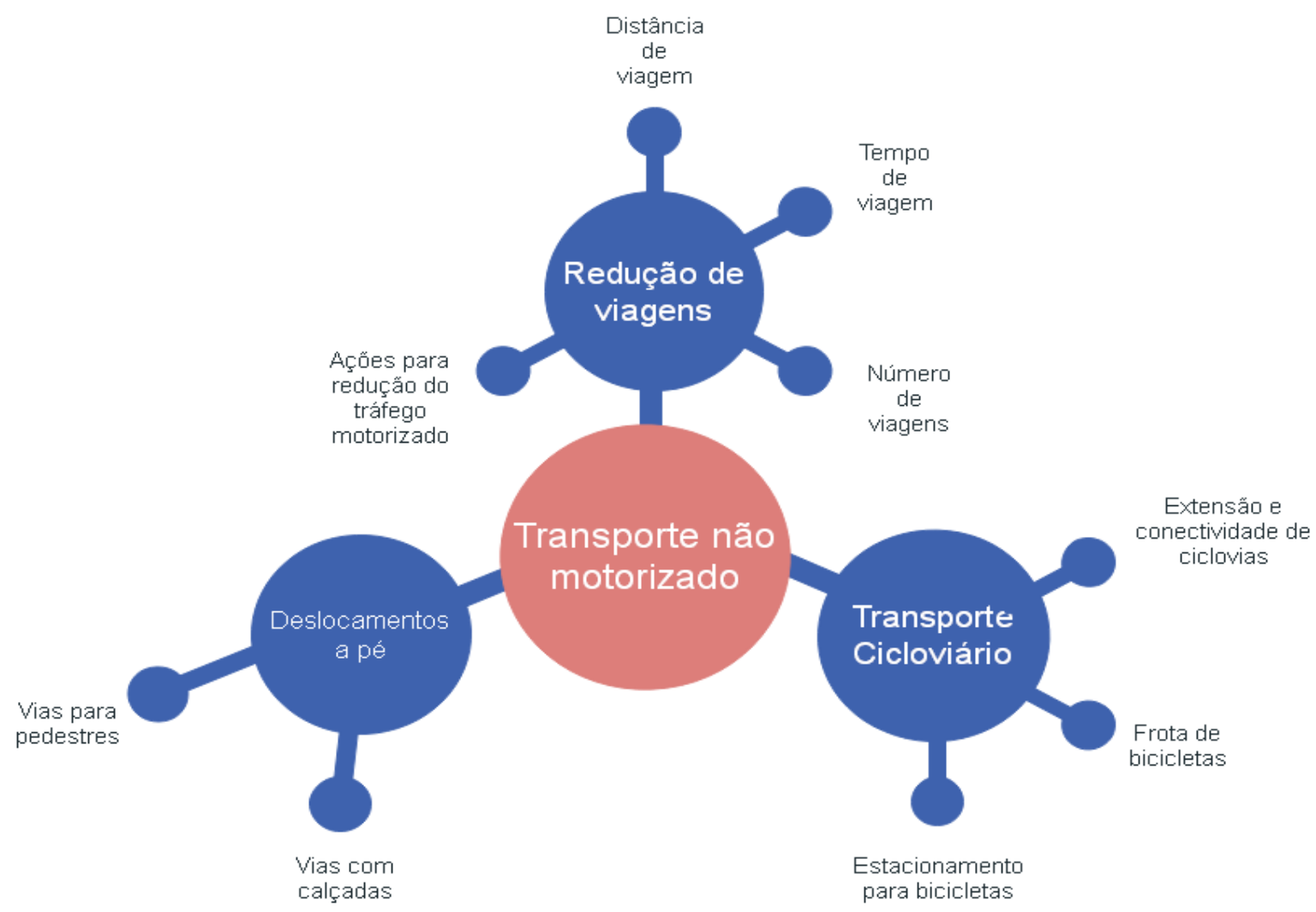

Fonte: Adaptado de Costa (2008).

\subsection{Extensão de ciclovias}

A figura 4 mostra o detalhamento do indicador e a figura 5 o mapa dos segmentos de ciclovias em São Carlos.

Figura 4 - Indicador de "Extensão de ciclovias".

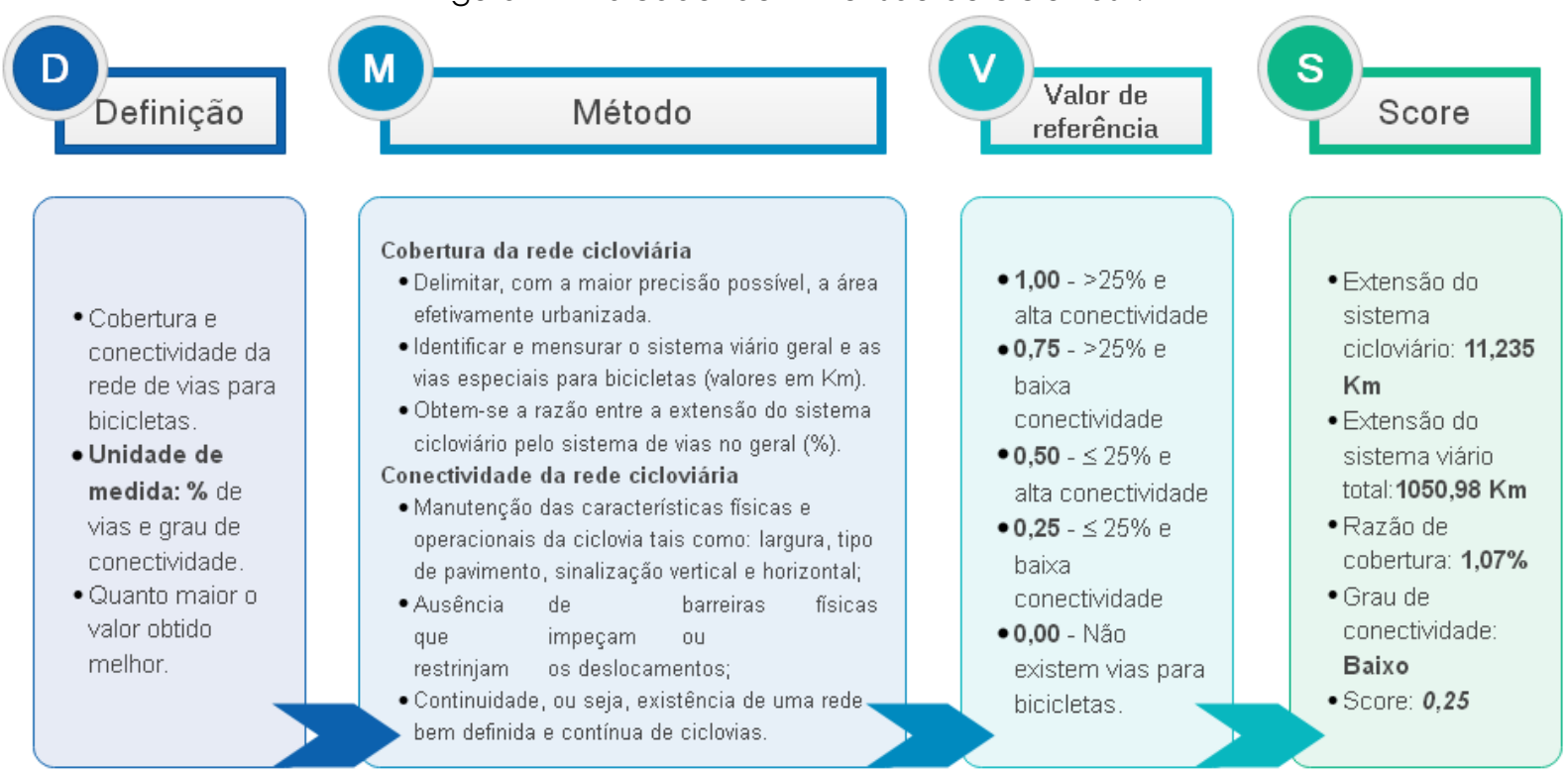

Fonte: Adaptado de Costa (2008). 
Figura 5 - Mapa dos trechos com ciclovias ou ciclofaixas em São Carlos-SP

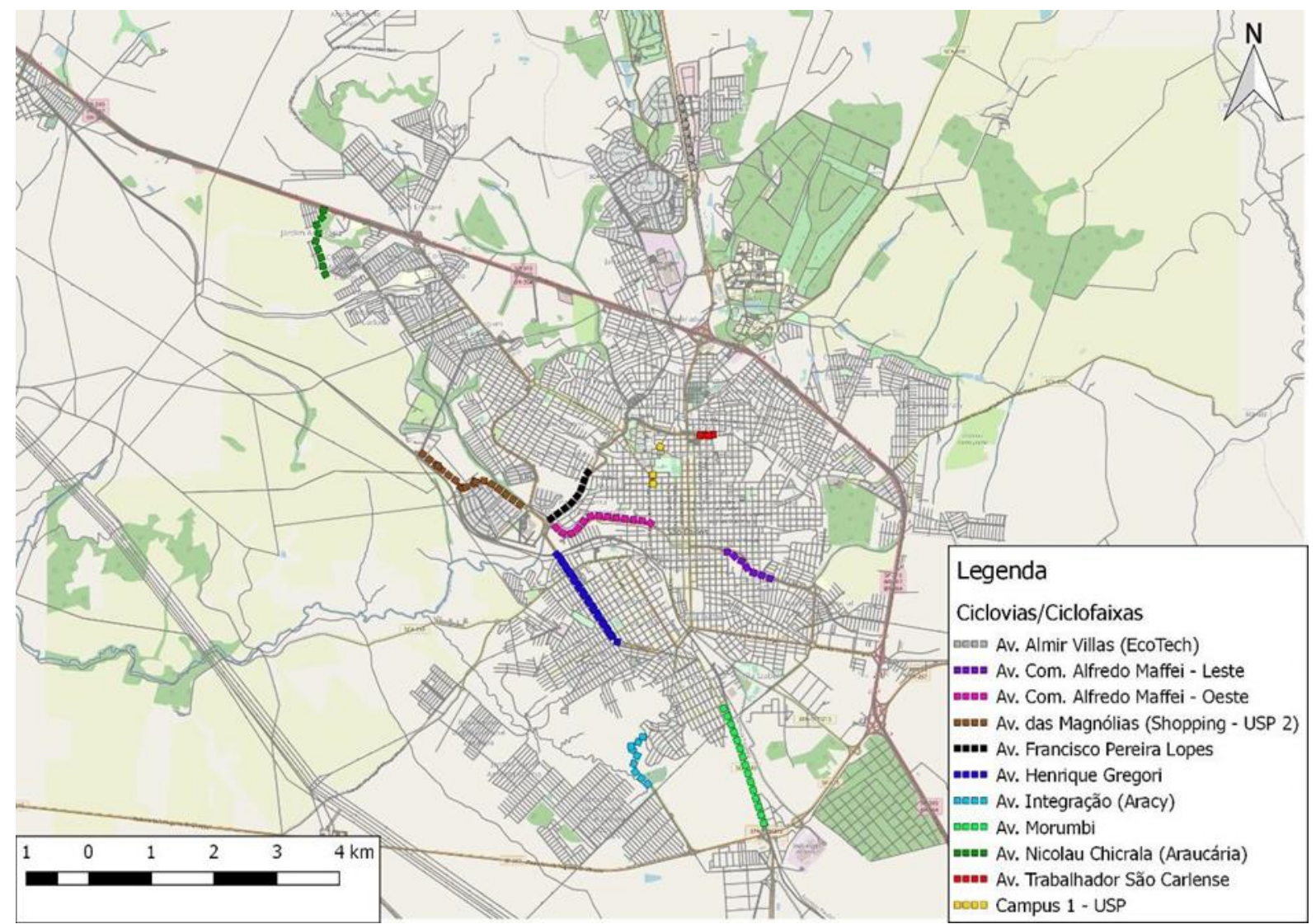

Fonte: Os autores (2018)

\subsection{Frota de bicicletas}

A figura 6 mostra o detalhamento do indicador.

Figura 6 - Indicador de "Frota de bicicletas".

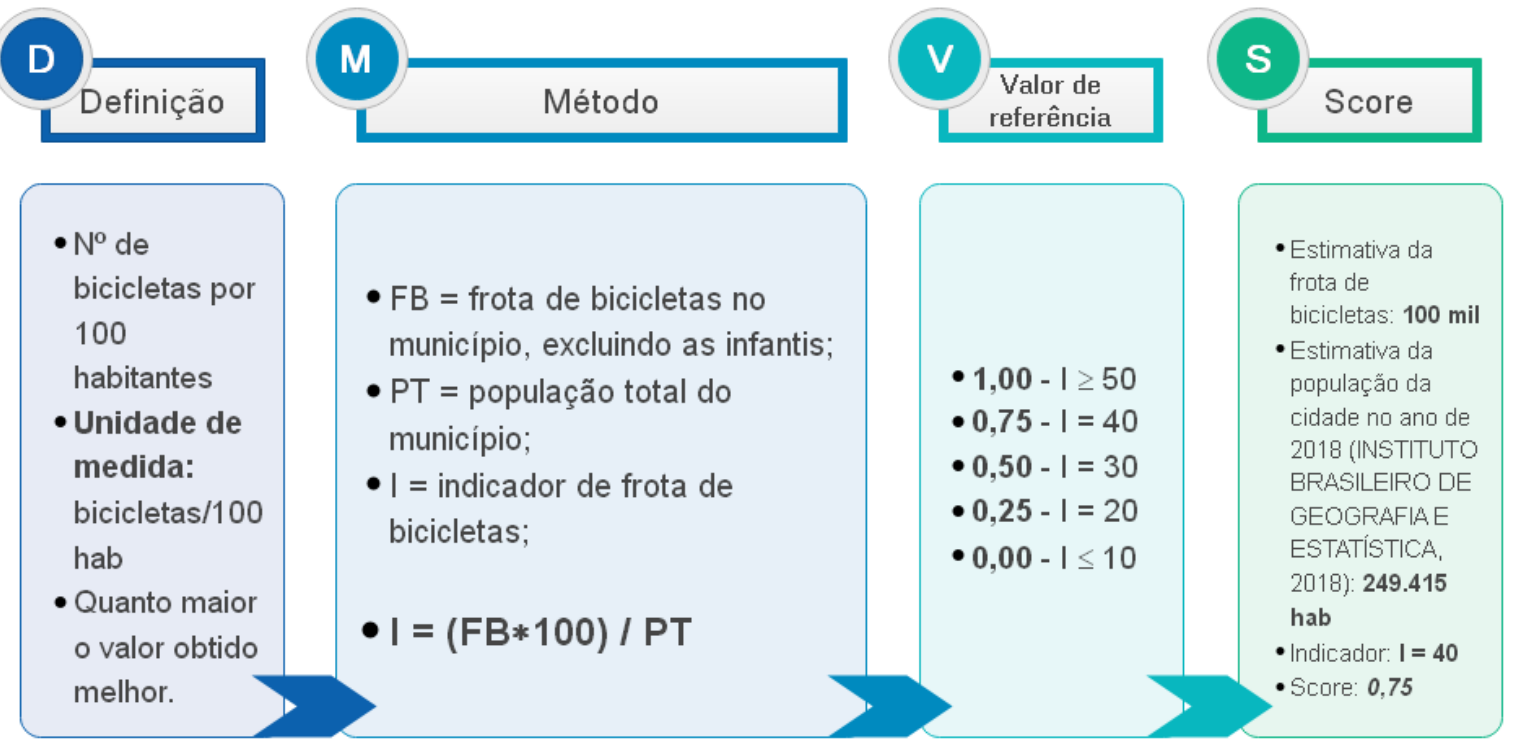




\subsection{Estacionamento para bicicletas}

A figura 7 mostra o detalhamento do indicador.

Figura 7 - Indicador de "Estacionamento para bicicletas".

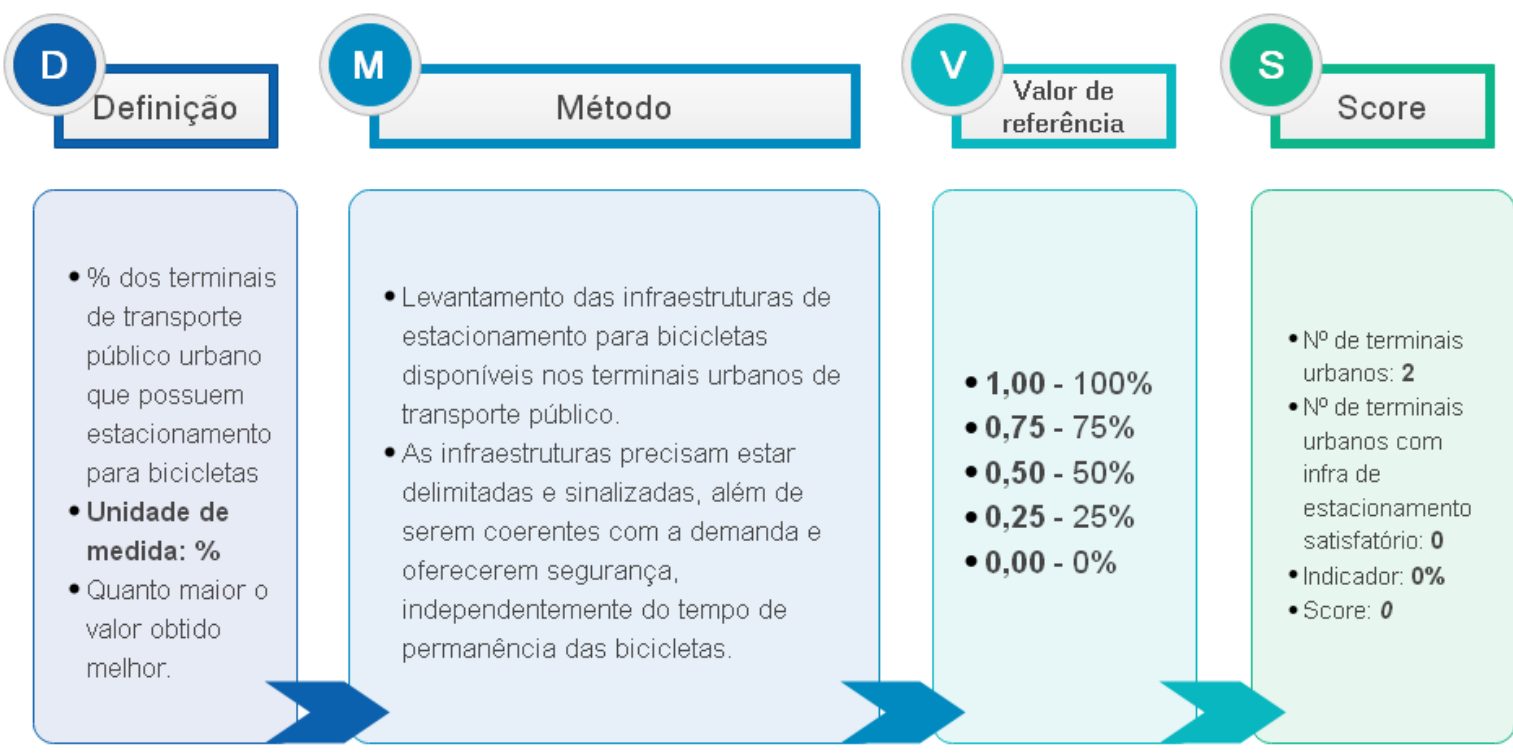

Fonte: Adaptado de Costa (2008)

\subsection{Vias para Pedestres}

A figura 8 mostra o detalhamento do indicador e a figura 9 o mapa dos segmentos de vias para pedestres em São Carlos.

Figura 8 - Indicador de "Vias para Pedestres".

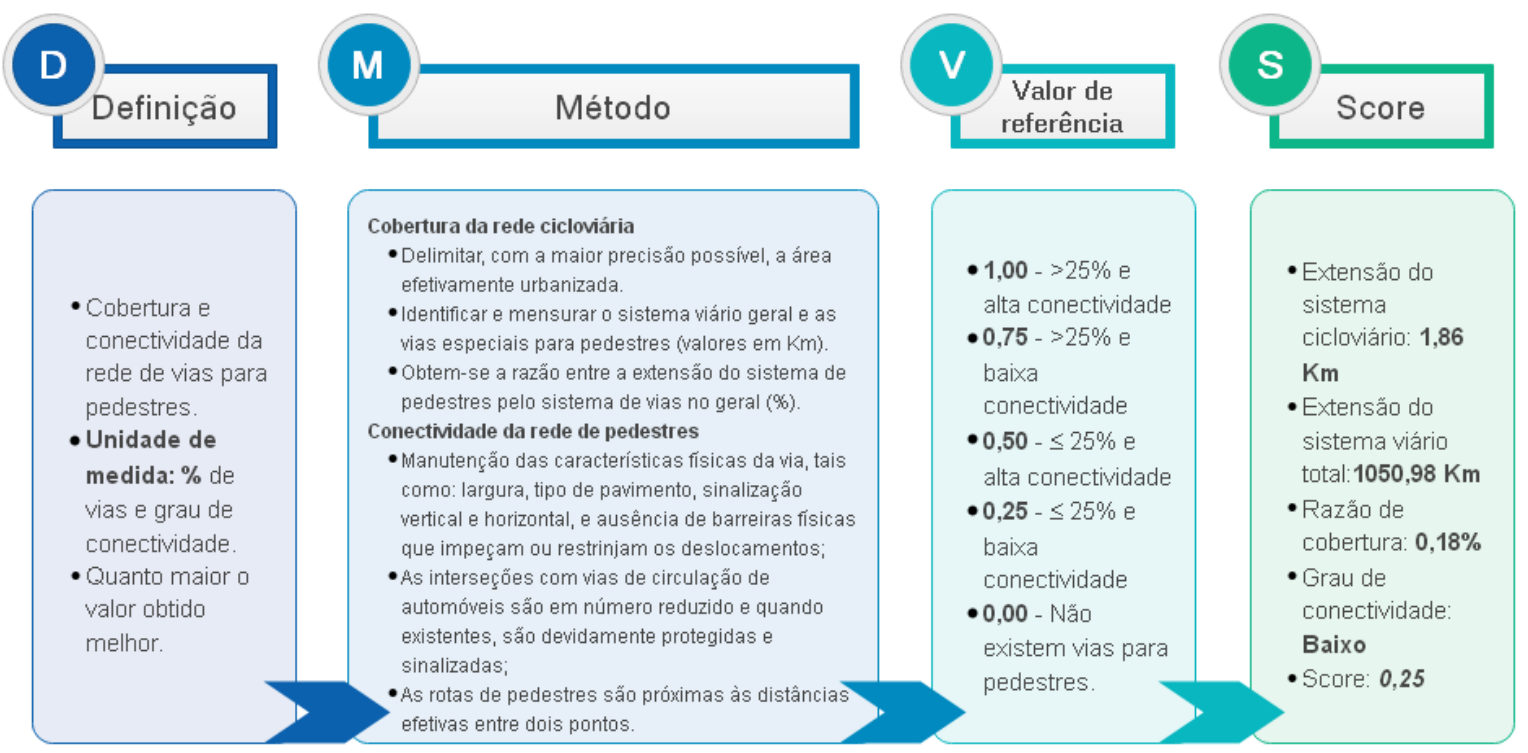

Fonte: Adaptado de Costa (2008) 
Figura 9 - Mapa dos trechos de vias exclusivas para pedestres em São Carlos-SP.

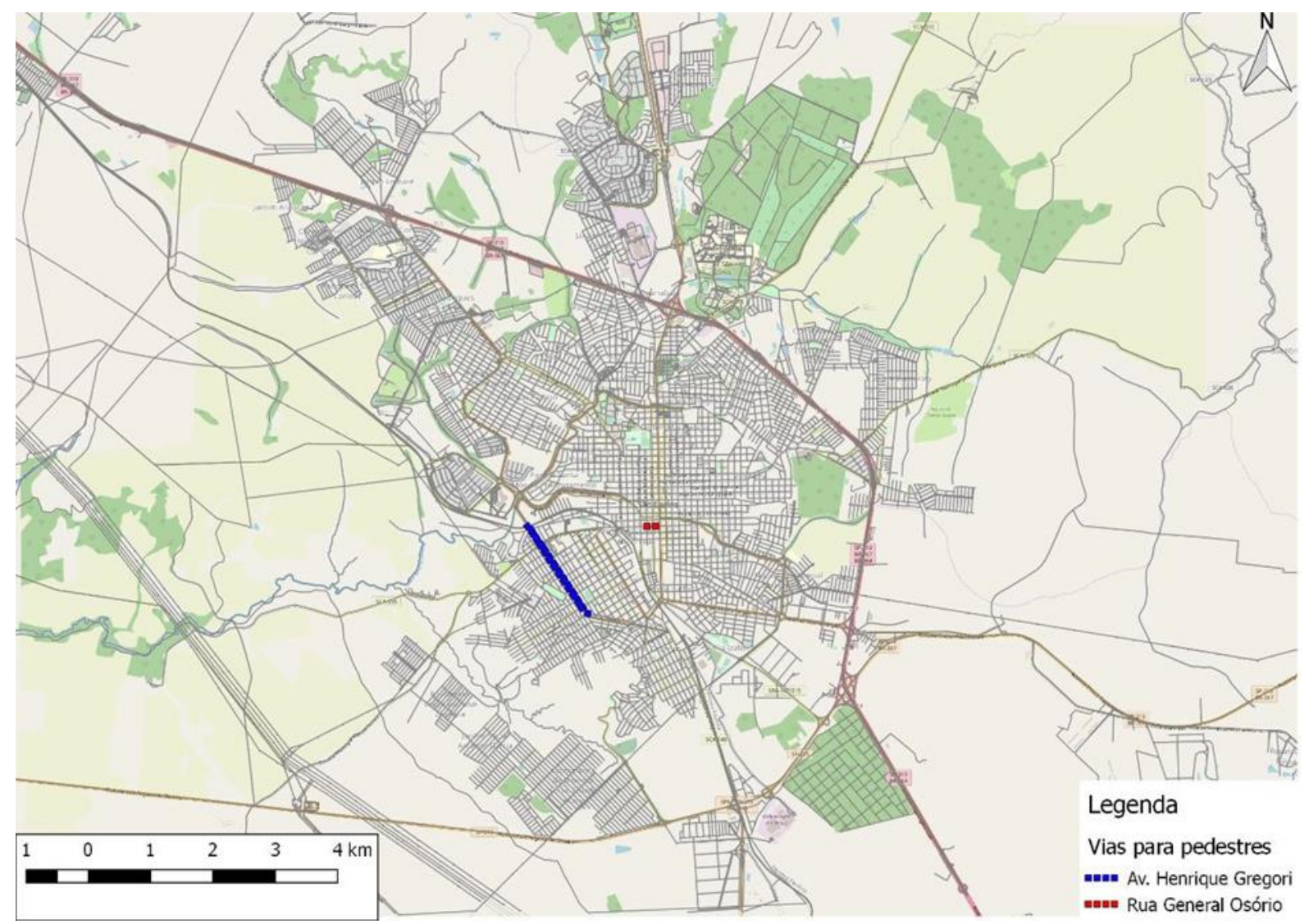

Fonte: Os autores (2018)

\subsection{Vias com Calçadas}

A figura 10 mostra o detalhamento do indicador.

Figura 10 - Indicador de "Vias com Calçadas".

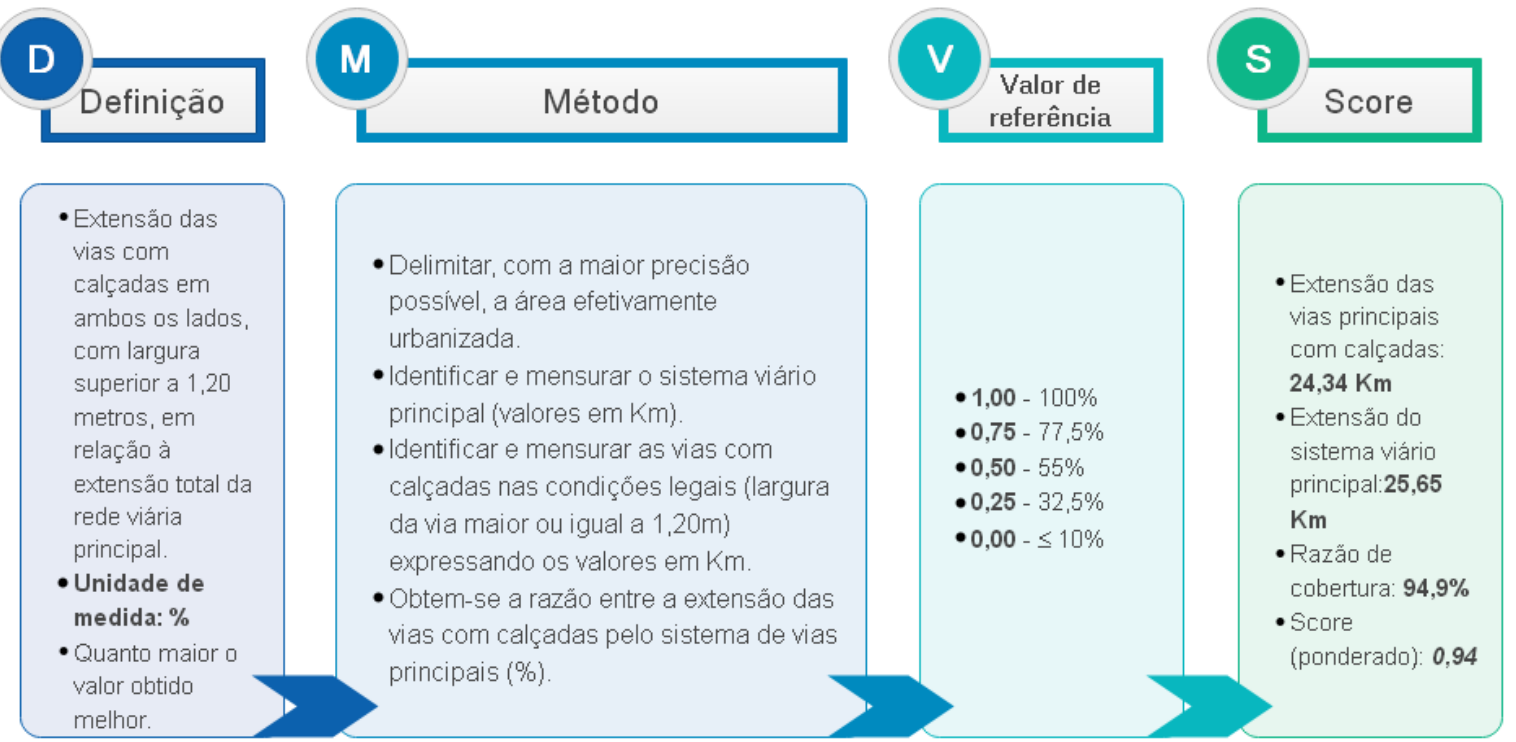

Fonte: Adaptado de Costa (2008) 


\subsection{Distância de Viagem}

A figura 11 mostra o detalhamento do indicador.

Figura 11 - Indicador de "Distância de Viagem".

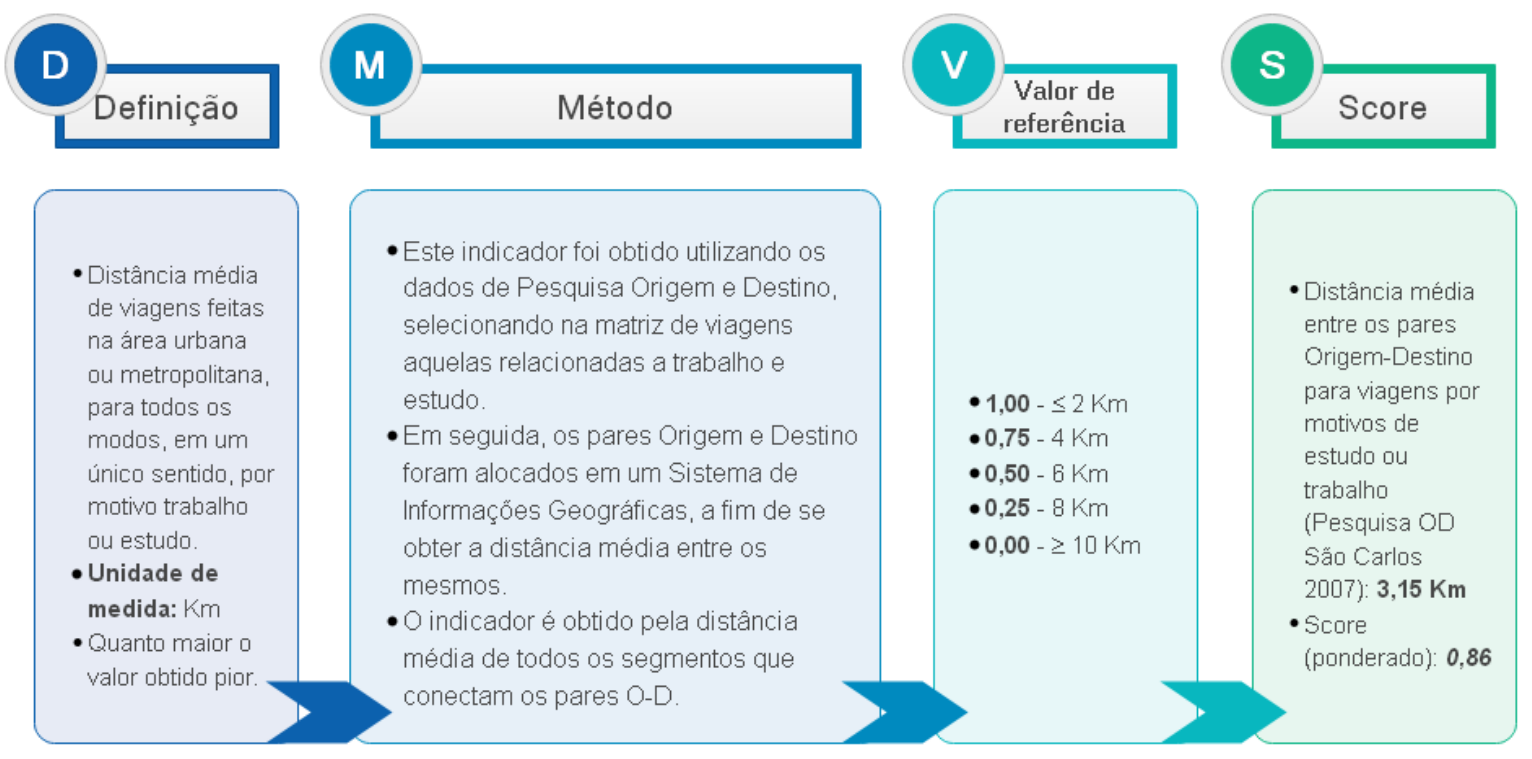

Fonte: Adaptado de Costa (2008)

\subsection{Tempo de Viagem}

A figura 12 mostra o detalhamento do indicador e a figura 13 as velocidades médias para cada modo de transporte.

Figura 12 - Indicador de "Tempo de Viagem".

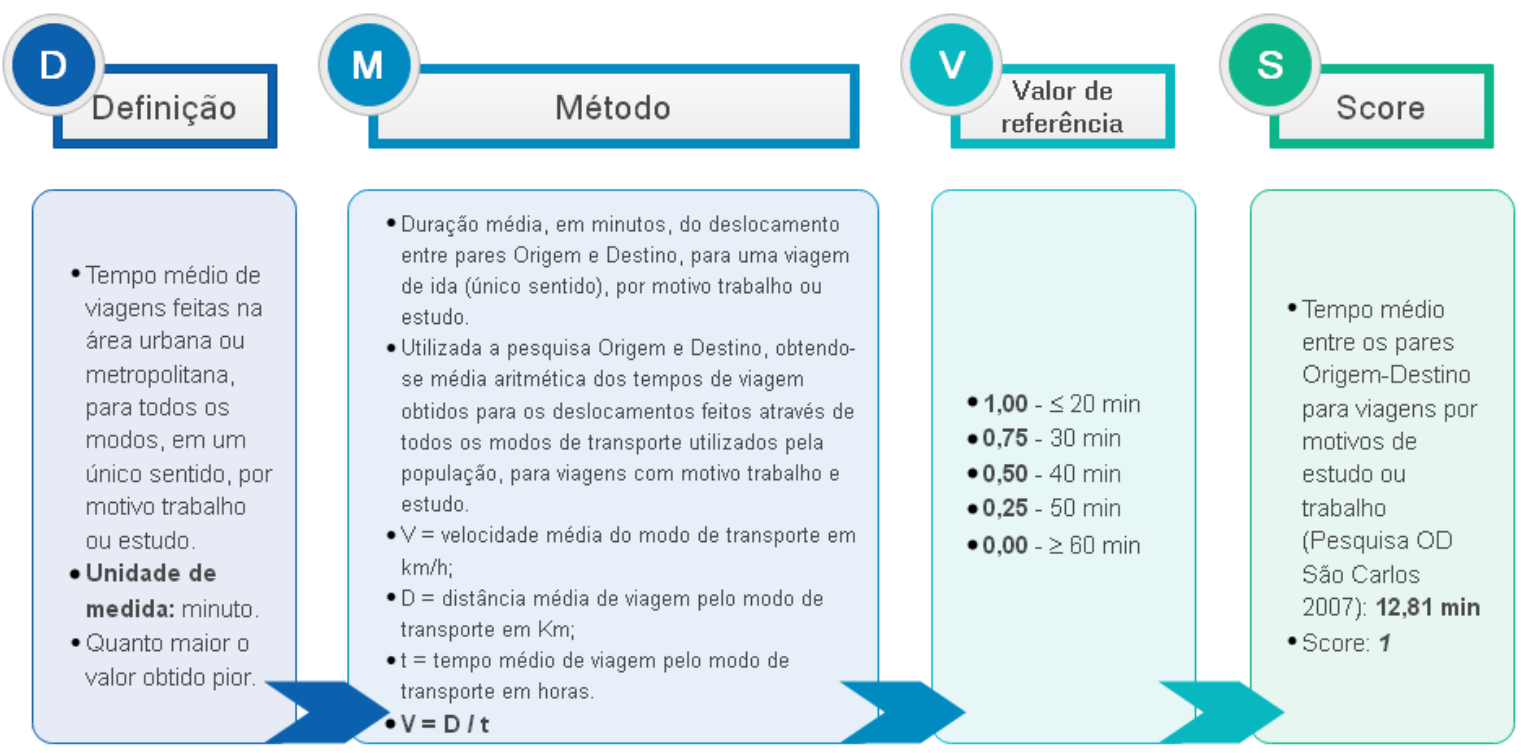

Fonte: Adaptado de Costa (2008) 
Figura 13 - Velocidades Médias para cada modo de transporte.

\section{Velocidades médias $(\mathrm{km} / \mathrm{h})$}

Para modais de transporte considerados no indicador

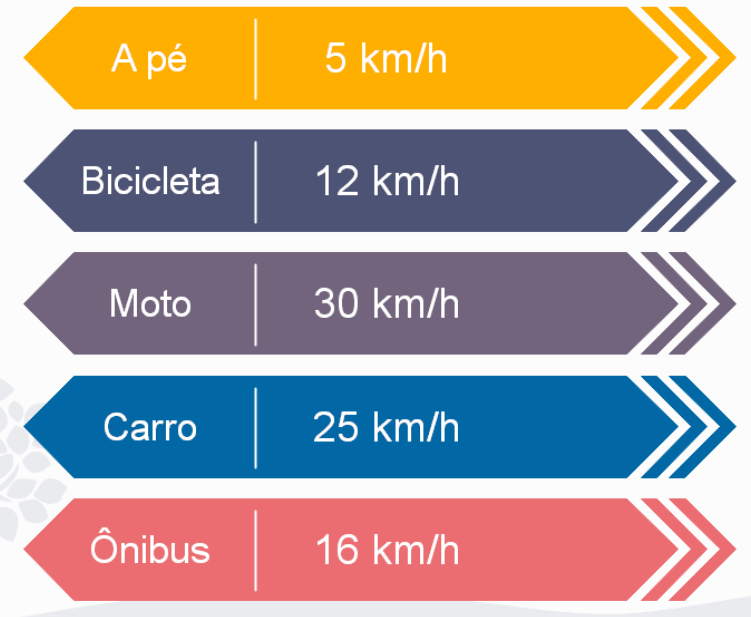

Fonte: Adaptado de Costa (2008)

\subsection{Número de Viagens}

A figura 14 mostra o detalhamento do indicador.

Figura 14 - Indicador de "Número de Viagens"

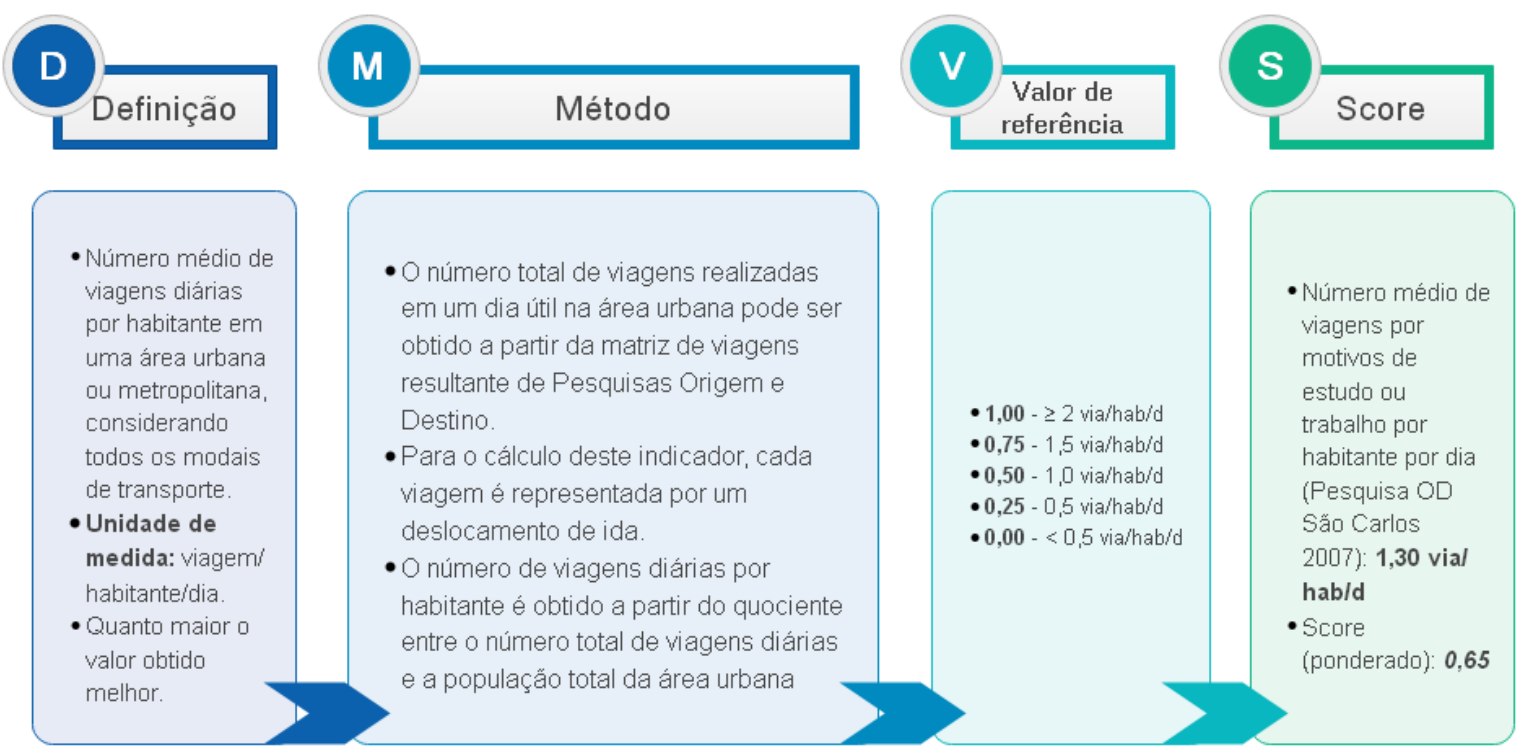

Fonte: Adaptado de Costa (2008)

\subsection{Ações para Redução do Tráfego Motorizado}

A figura 15 mostra o detalhamento do indicador. 
Figura 15 - Indicador de "Ações para Redução do Tráfego Motorizado"

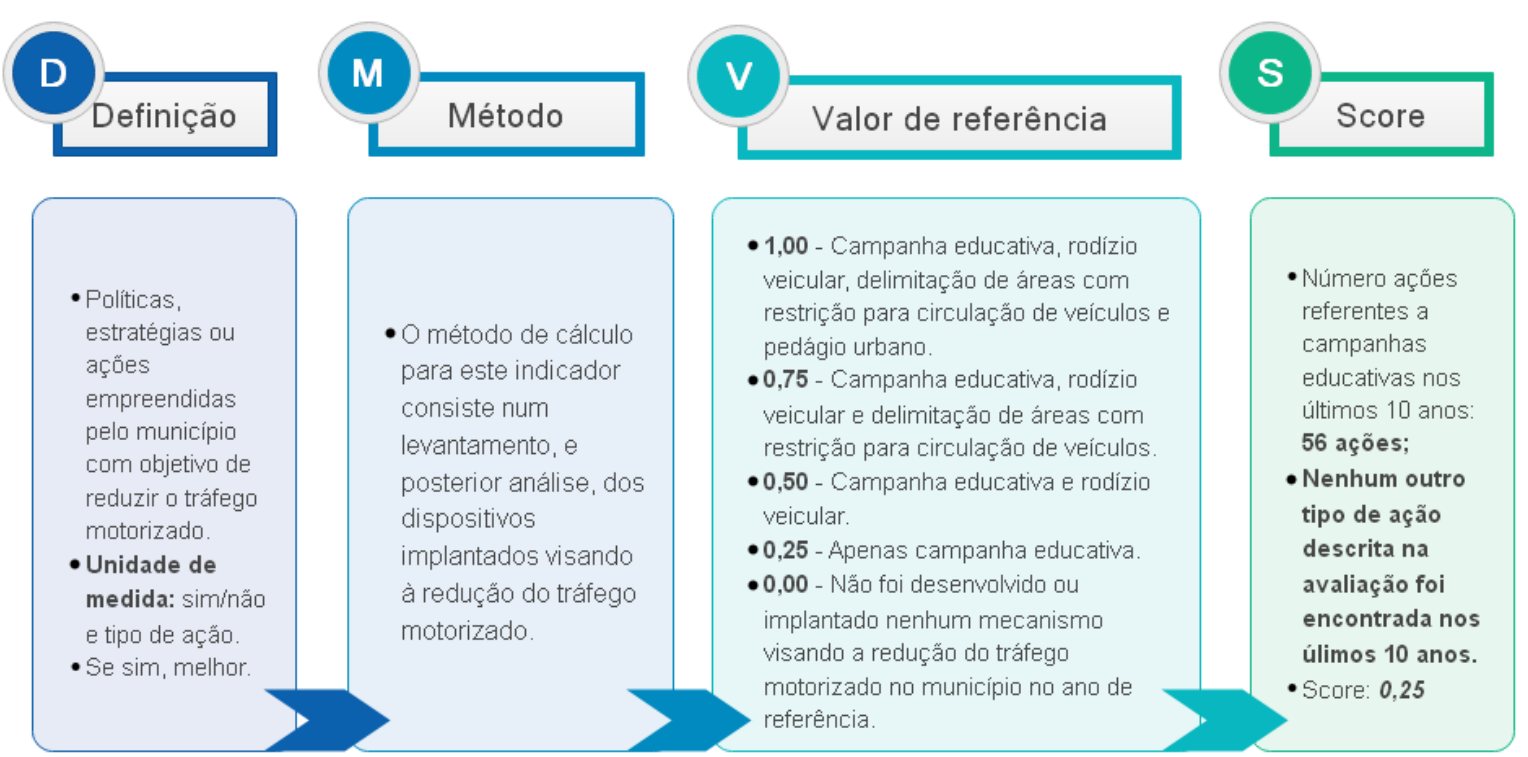

Fonte: Adaptado de Costa (2008)

\section{RESULTADOS E DISCUSSÕES}

O IMUS traz ponderações no cálculo dos indicadores considerando o domínio, o tema e o indicador em si. Considerando que o trabalho se realizou dentro do domínio de transporte não-motorizado, somente serão considerados os pesos de tema e indicador. Os pesos estão definidos na figura 16.

Figura 16 - Pesos dos indicadores

\section{Pesos dos temas e indicadores}

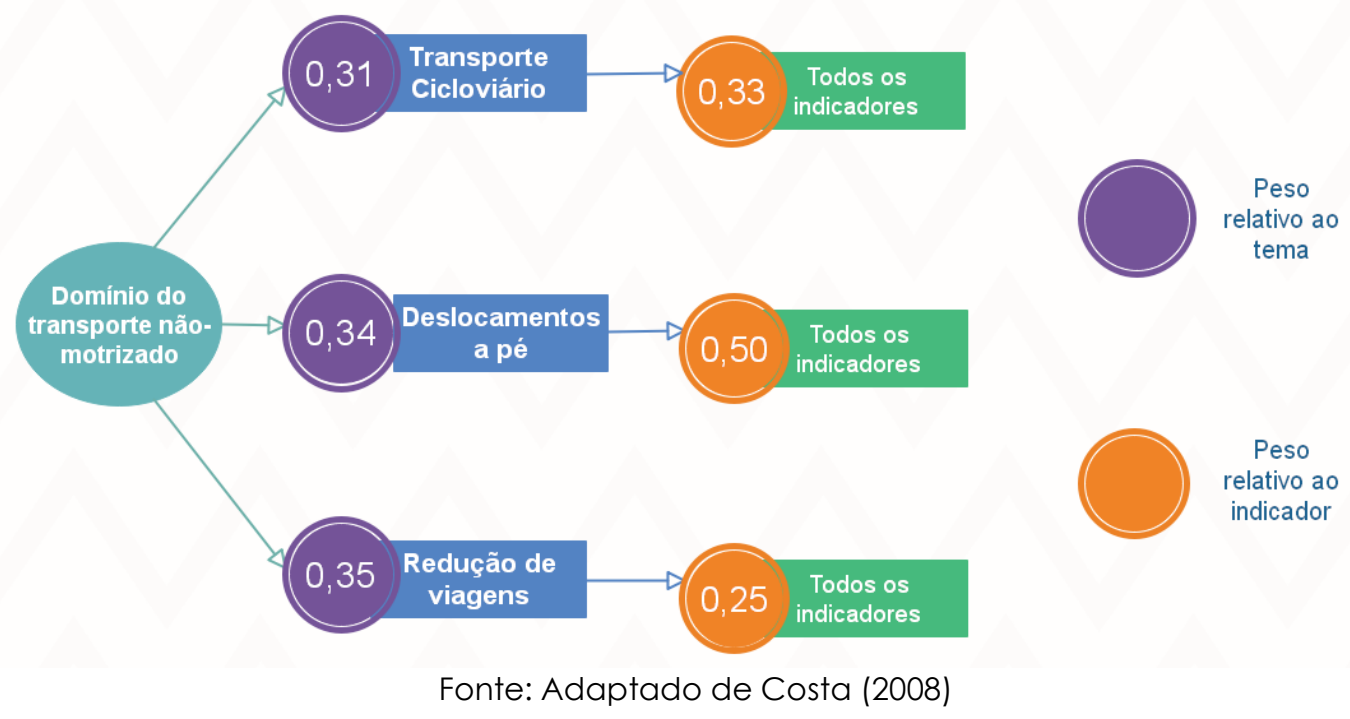

Com os escores brutos obtidos para cada indicador e os pesos para cada caso, foram obtidos os escores ponderados. Aplicando as ponderações nos resultados de 2008, foi criada a figura 17, que traz a comparação dos resultados de aplicação do IMUS. 


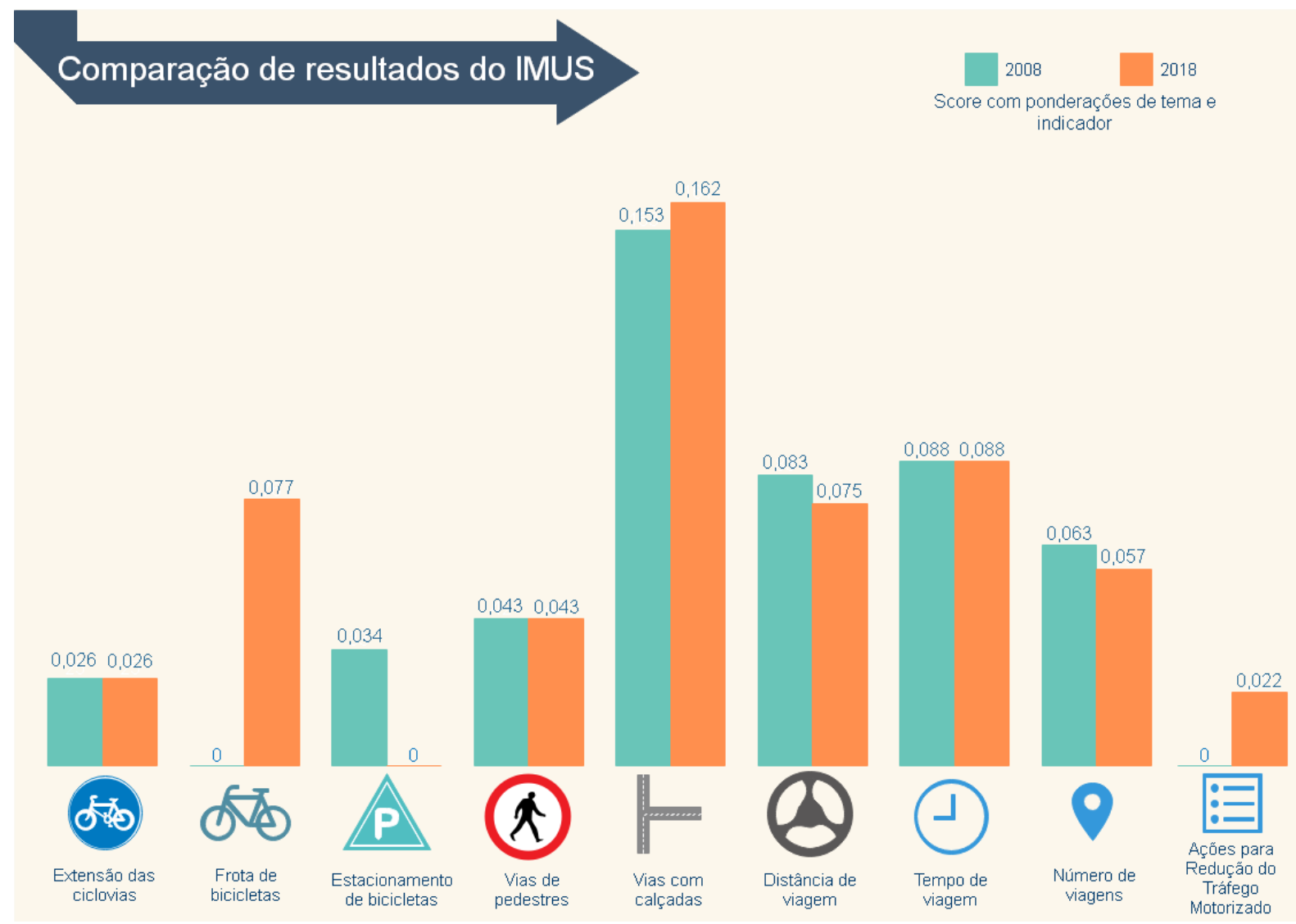

Fonte: Os autores (2018)

A soma do score total ponderado para o domínio de transporte não-motorizado foi de $\mathbf{0 , 4 8 8}$ para 2008 e 0,548 em 2018, um aumento de $12 \%$ em 10 anos. O transporte não motorizado tem peso de $\mathbf{0 , 1 1}(\mathbf{1 1 \%})$ dentro do IMUS como um todo, sendo, em ordem do maior para o menor peso, o quinto lugar de um total de 9 domínios.

\section{CONCLUSÕES}

Cada vez mais, a Mobilidade Urbana vem ganhando espaço nas discussões públicas, sejam por parte da administração pública ou da população. Estudar fenômenos da mobilidade em termos de sua sustentabilidade é uma necessidade ainda mais atual. Logo, indicadores de mobilidade urbana sustentável têm sua importância elevada, pois podem (e devem) ser utilizados como argumentos para que haja medidas assertivas no planejamento $e$ desenvolvimento da cidade quanto à mobilidade urbana.

O IMUS foi reaplicado para realização de uma comparação temporal. Não foi detectado nenhum problema ou desatualização de grave na estrutura elaborada por Costa (2008). Entretanto, alguns pontos da metodologia devem ser observados, como mostra a figura 18. 


\section{Observações sobre o IMUS}

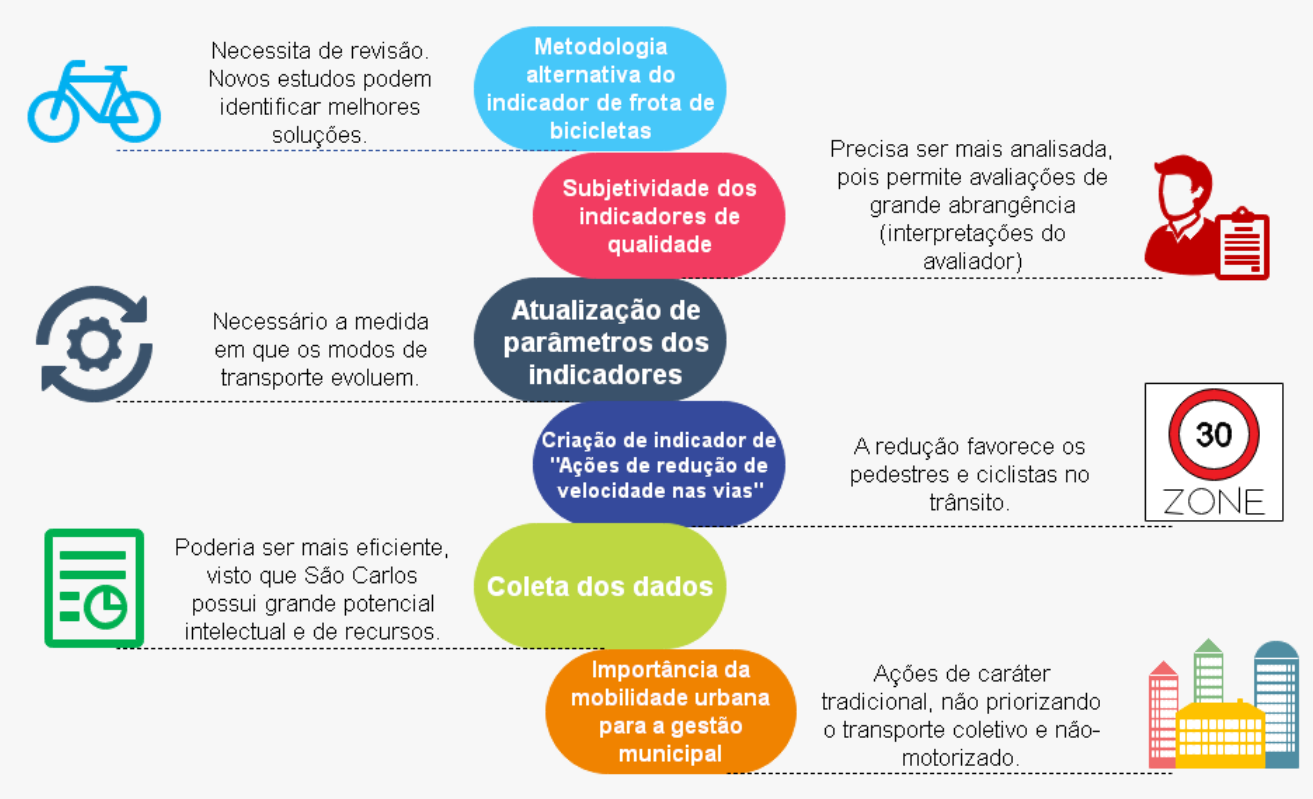

Fonte: Os autores (2018)

Em virtude da comparação feita, mostrando um acréscimo de $12 \%$ no score em 10 anos, percebe-se que esse período parece ter sido pouco para a evolução da cidade de São Carlos na mobilidade urbana: faltam ciclovias, falta infraestrutura para integração dos modais, falta informação acessível a respeito do transporte urbano, faltam investimentos em pesquisa e obras e, por fim, faltam políticas públicas que colaborem para o amplo conhecimento acerca das necessidades de uma mobilidade planejada, acessível e sustentável. A reavaliação mostra os pontos que precisam de mais atenção do poder público, como inclusão de ações que valorizem mobilidade sustentável, bem como pontos que podem ser incluídos no índice, como novos indicadores a respeito das áreas que ficaram mais defasadas nas atribuições de pesos.

\section{REFERÊNCIAS}

BRASIL. LEI No 12.587, DE 3 DE JANEIRO DE 2012. 2012. Disponível em: <http://www.planalto.gov.br/ccivil_03/_ato2011-2014/2012/lei/l12587.htm>. Acesso em: 24 abr. 2018.

BRASIL. MINISTÉRIO DAS CIDADES. PlanMob: caderno de referência para elaboração de plano de mobilidade urbana. Disponível em: <http://www.cidades.gov.br/images/stories/Ar quivosSE/planmob.pdf>. Acesso em: 23 abr. 2018.

\section{CAMPOS, V. B. G.; RAMOS, R. A. R. PROPOSTA DE INDICADORES DE MOBILIDADE URBANA} SUSTENTÁVEL RELACIONANDO TRANSPORTE E USO DO SOLO. [s. I.], 2005. Disponível em: <http://aquarius.ime.eb.br/ webde2/prof/vania/pubs/(21)INDICADORES.pdf> . Acesso em: 24 abr. 2018. 
COSTA, M. C. (2008). Um índice de mobilidade urbana sustentável. Tese de Doutorado, Escola de Engenharia de São Carlos, Universidade de São Paulo, São Carlos.

GUDMUNDSSON, H. (2004). Sustainable Transport and Performance Indicators. Issues in Environmental Science and Technology, 20, p. 35-64, 2004.

INSTITUTO BRASILEIRO DE GEOGRAFIA E ESTATÍSTICA - IBGE | Projeção da população. 2010. Disponível em: <https://www.ibge.gov.br/apps/populacao/projecao/>. Acesso em: 24 abr. 2018.

INSTITUTO BRASILEIRO DE GEOGRAFIA E ESTATÍSTICA - IBGE. Cidades. Disponível em: <http://w Ww.ibge.gov.br/cidadesat/default.php>.

Acesso em: 19 nov. 2018.

PESQUISA ORIGEM-DESTINO (OD). Projeto de pesquisa financiado pela FAPESP (Fundação de Amparo à Pesquisa do Estado de São Paulo). Número de referência: 04/15843- 4. 2007d. 